\title{
Augmented PMMA distribution: improvement of mechanical property and reduction of leakage rate of a fenestrated pedicle screw with diameter-tapered perforations
}

\author{
*Quan-chang Tan, MS, $, 1,2$ Jian-wei Wu, MS, ${ }^{1}$ Fei Peng, MS, ${ }^{1}$ Yuan Zang, MD, PhD, ${ }^{1}$ Yang Li, MS, \\ Xiong Zhao, MD, PhD, ${ }^{1}$ Wei Lei, MD, PhD, ${ }^{1}$ and Zi-xiang Wu, MD, PhD'
}

'Department of Orthopaedics, Xijing Hospital, the Fourth Military Medical University, Xi'an Shaanxi Province; and 'Department of Orthopaedics, 454 Hospital of PLA, Nanjing, Jiangsu Province, People's Republic of China

\begin{abstract}
OBJECTIVE This study investigated the optimum injection volume of polymethylmethacrylate (PMMA) to augment a novel fenestrated pedicle screw (FPS) with diameter-tapered perforations in the osteoporotic vertebral body, and how the distribution characteristics of PMMA affect the biomechanical performance of this screw.

METHODS Two types of FPSs were designed (FPS-A, composed of 6 perforations with an equal diameter of $1.2 \mathrm{~mm}$; and FPS-B, composed of 6 perforations each with a tapered diameter of $1.5 \mathrm{~mm}, 1.2 \mathrm{~mm}$, and $0.9 \mathrm{~mm}$ from tip to head. Each of 28 human cadaveric osteoporotic vertebrae were randomly assigned to 1 of 7 groups: FPS-A1.0: FPS-A+1.0 ml PMMA; FPS-A1.5: FPS-A+1.5 ml PMMA; FPS-A2.0: FPS-A+2.0 ml PMMA; FPS-B1.0: FPS-B+1.0 ml PMMA; FPS-B1.5: FPS-B+1.5 ml PMMA; FPS-B2.0: FPS-B+2.0 ml PMMA; and conventional pedicle screws (CPSs) without PMMA. After the augmentation, 3D CT was performed to assess the cement distribution characteristics and the cement leakage rate. Axial pullout tests were performed to compare the maximum pullout force thereafter.
\end{abstract}

RESULTS The CT construction images showed that PMMA bone cement formed a conical mass around FPS-A and a cylindrical mass around FPS-B. When the injection volume was increased from $1.0 \mathrm{ml}$ to $2.0 \mathrm{ml}$, the distribution region of the PMMA cement was enlarged, the PMMA was distributed more posteriorly, and the risk of leakage was increased. When the injection volume reached $2.0 \mathrm{ml}$, the risk of cement leakage was lower for screws having diameter-tapered perforations. The pullout strengths of the augmented FPS-A groups and FPS-B groups were higher than that of the CPS group ( $p$ 0.0001). All FPS-B groups had a higher pullout strength than the FPS-A groups.

CONCLUSIONS The diameter of the perforations affects the distribution of PMMA cement. The diameter-tapered design enabled PMMA to form larger bone-PMMA interfaces and achieve a relatively higher pullout strength, although statistical significance was not reached. Study results indicated $1.5-\mathrm{ml}$ of PMMA was a conservative volume for PMMA augmentation; more cement injection would significantly increase the risk of cement leakage.

http://thejns.org/doi/abs/10.3171/2015.10.SPINE141275

KEY WORDS cement distribution; fenestrated pedicle screws; cement augmentation; osteoporosis; polymethylmethacrylate; PMMA; vertebral body

$\mathrm{T}$ HE transpedicular fixation technique has been used in the treatment of spinal disorders ${ }^{11,22}$ and can provide sufficient stability via 3-column fixation. However, its advantages are highly dependent on the bone quality of the vertebrae. Therefore, the weak placement of the screw in osteoporotic vertebrae in the aging popula- tion remains a considerable challenge faced by spine surgeons. ${ }^{6,15,20,23,26,27}$ Additionally, the risk of fixation failure due to screw loosening increases significantly in patients with osteoporotic bone..$^{30}$

Many new implants have been studied to enhance screw fixation in osteoporotic spines, including the expandable

ABBREVIATIONS A-L = anterior and lateral; $B M D=$ bone mineral density; $C P S=$ conventional pedicle screw; $F_{\max }=$ maximum load; FPS = fenestrated pedicle screw; $\mathrm{PMMA}=$ polymethylmethacrylate; $\mathrm{VB}=$ vertebral body.

SUBMITTED December 18, 2014. ACCEPTED October 6, 2015

INCLUDE WHEN CITING Published online February 5, 2016; DOI: 10.3171/2015.10.SPINE141275

${ }^{*}$ Mr. Tan and Mr. Wu contributed equally to this work. 
pedicle screw, ${ }^{20,34}$ fenestrated pedicle screw (FPS), ${ }^{1,26}$ modified thread-design screw, ${ }^{23}$ hydroxyapatite-coated screw, ${ }^{29,32}$ and polymethylmethacrylate (PMMA) augmentation. ${ }^{20,31}$ Among these approaches, the FPSs augmented by PMMA has achieved the highest fixation strength and best clinical outcomes ${ }^{1,26}$. However, disadvantages remain, such as bone-cement leakage, ${ }^{3}$ exothermic damage, ${ }^{19,28}$ and pulmonary embolism. ${ }^{2,13}$

The aims of this study were as follows: 1) to investigate the optimum injection volume of PMMA to augment a novel FPS with diameter-tapered perforations in an osteoporotic vertebral body (VB) to minimize the risk of cement leakage, and 2) to evaluate how the distribution characteristics of PMMA affect the biomechanical performance of the FPS.

\section{Methods \\ Screw Design}

FPS-A (Fig. 1 left) and FPS-B (Fig. 1 right) (Weigao Orthopedic Device Co. Ltd.) have an identical length of $45.0 \mathrm{~mm}$, outer diameter of $6.5 \mathrm{~mm}$, and central bore diameter of $1.6 \mathrm{~mm}$. The detailed characteristics of the screws are listed in Table 1. FPS-B was approved by the State Food and Drug Administration of China (Approval No. 3460258).

\section{Specimen Preparation}

Vertebrae (T10-L5) were obtained from the fresh-frozen human cadaveric spine of 1 man and 4 women, with ages ranging from 72 to 85 years (average age 79 years). All of the vertebrae underwent anterior-posterior and lateral radiography to exclude congenital deformity, vertebral fracture, tumor, and other abnormalities. Dual-energy x-ray absorptiometry scanning (QDR-4500 SL; Hologic) was conducted to determine the bone mineral density (BMD) of the vertebrae. All of the intervertebral discs, muscles, ligaments, and residual soft tissues were dissected from the cadaveric spine. Then, the cadaveric spine was disarticulated into single vertebrae. A total of 28 vertebrae were included in the study. Single vertebrae were sealed in the specimen bag and stored at $-20^{\circ} \mathrm{C}$ until the experiment was commenced. Twenty-four hours before the experiment, the specimens were completely thawed at ambient temperature.

This study was approved by the medical ethics committee of Fourth Military Medical University.

\section{Screw Insertion and Augmentation}

A total of 56 screw trajectories in 28 vertebrae were randomized into 7 groups: FPS-A augmented with $1.0 \mathrm{ml}$ of PMMA bone cement (FPS-A1.0 group), FPS-A augmented with $1.5 \mathrm{ml}$ of PMMA bone cement (FPS-A1.5 group), FPS-A augmented with $2.0 \mathrm{ml}$ of PMMA bone cement (FPS-A2.0 group), FPS-B augmented with $1.0 \mathrm{ml}$ of PMMA bone cement (FPS-B1.0 group), FPS-B augmented with $1.5 \mathrm{ml}$ of PMMA bone cement (FPS-B1.5 group), FPS-B augmented with $1.5 \mathrm{ml}$ of PMMA bone cement (FPS-B2.0 group), and conventional pedicle screws (CPSs) without augmentation (CPS group). Each group had 8 screw trajectories (Table 2).
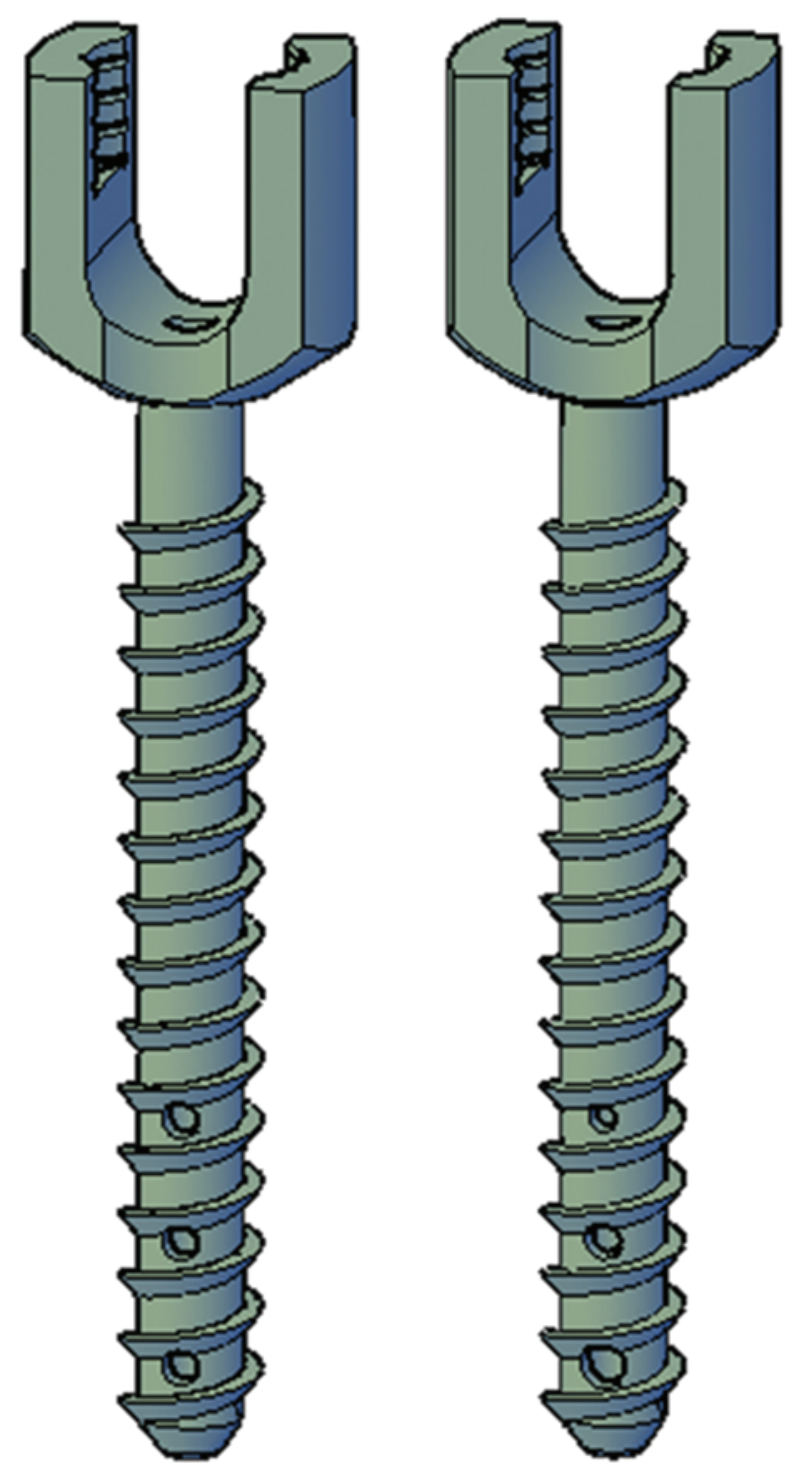

FIG. 1. Schematic images of the FPSs used in this study. Left: FPS-A. Right: FPS-B. Figure is available in color online only.

All procedures involved in the screw insertion and augmentation were conducted by an experienced surgeon (Z.X.W.). The entry point of the screw was located at the intersection of the horizontal line of the transverse process midpoint and the vertical line of the articular process exterior margin. The cortex overlying the landmark of the entry point was removed with a grinding borer. Then, the pilot hole was drilled and the screw was inserted with or without PMMA augmentation. PMMA bone cement (Tianjing Institute of Synthetic Materials Industry) was mixed at a powder-to-liquid ratio of 2:1. After mixing for approximately 3 minutes, the PMMA was loaded into a customized syringe. To minimize the effects of the injection speed on cement leakage, all PMMA cement was injected at the same speed. The PMMA procedure was carried out without radiographic monitoring to observe the natural distribution characteristics of the PMMA bone cement. 
TABLE 1. Parameters of pedicle screws

\begin{tabular}{lrrr}
\hline & \multicolumn{3}{c}{ Type of Screw } \\
\cline { 2 - 4 } \multicolumn{1}{c}{ Parameter } & FPS-A & FPS-B & CPS \\
\hline Length $(\mathrm{mm})$ & 45.0 & 45.0 & 45.0 \\
\hline Outer diameter $(\mathrm{mm})$ & 6.5 & 6.5 & 6.5 \\
\hline Inner diameter $(\mathrm{mm})$ & 1.6 & 1.6 & 0.0 \\
\hline No. of threads & 15.0 & 15.0 & 15.0 \\
\hline Thread pitch $(\mathrm{mm})$ & 3.0 & 3.0 & 3.0 \\
\hline No. of perforations & 6.0 & 6.0 & 0.0 \\
\hline Perforation diameter $(\mathrm{mm})$ & $1.2,1.2,1.2$ & $0.9,1.2,1.5$ & 0.0 \\
\hline
\end{tabular}

\section{CT Scanning}

The distribution of bone cement in augmented vertebrae was assessed by CT scanning (PQ6000; Picker International) with the following parameters: voltage 120 $\mathrm{kV}, 200-\mathrm{mA}$ tube current, 3-mm scanning slice thickness, 2-mm scanning slice distance, $1.5-\mathrm{mm}$ spiral distance, and 1.5-msec scanning time. 3D CT reconstruction was conducted with VoxelQ software (Picker International). The 3D CT images were examined carefully from multiple angles and directions to ensure the position relationship of vertebra, pedicle screw, and PMMA bone cement. The reconstructed images allowed for a thorough and accurate evaluation of the position relationship of screw, vertebra, and PMMA bone cement.

\section{Pullout Test}

A pullout test was performed on a servohydraulic testing machine (MTS585; MTS Systems) to evaluate the fixation strength. The protocol used was according to Mehta et al.,23 who performed their experiment based on the Standard Specification and Test Methods for Metallic Medical Bone Screws (ASTM F543-07). Briefly, the vertebra was fixed to a custom-made clamper subjected to load frame and the screw head was attached to the load fixture. The longitudinal axis of the screw was adjusted in the same direction as the applied load. A tensile load was applied to the screw at a constant rate of $5 \mathrm{~mm} / \mathrm{min}$ until the screw was released from the vertebra. Load-displacement data were automatically collected and analyzed. The maximum load applied was recorded as $\mathrm{F}_{\max }$. The test order of the 2 screws in 1 vertebra was randomized to eliminate the effects of the testing order that could affect the value of $F_{\max }$.

\section{Statistical Analysis}

Data analysis was performed using GraphPad Prism 5.0 (GraphPad Software). One-way ANOVA was used to compare the pullout strength between FPS-A and CPS. Then, Dunnett's multiple comparisons test was applied to detect the differences between FPS-A1.0 and CPS, FPSA1.5 and CPS, and FPS-A2.0 and CPS. ANOVA was used to compare the difference in pullout strength between FPS-B and CPS. Then, Dunnett's multiple comparisons test was applied to detect the differences between FPSB1.0 and CPS, FPS-B1.5 and CPS, and FPS-B2.0 and CPS. Student t-test was used to determine the difference
TABLE 2. Pullout strength in PMMA-augmented FPS groups and the CPS group

\begin{tabular}{cccc}
\hline Groups & $\begin{array}{c}\text { No. of Screw } \\
\text { Trajectories }\end{array}$ & $\begin{array}{c}\text { PMMA Vol } \\
(\mathrm{ml})\end{array}$ & Pullout Strength $(\mathrm{N})$ \\
\hline FPS-A1.0 & 8 & 1.0 & $395.63 \pm 88.83$ \\
\hline FPS-A1.5 & 8 & 1.5 & $600.63 \pm 170.01^{*}$ \\
\hline FPS-A2.0 & 8 & 2.0 & $766.50 \pm 165.32^{*}$ \\
\hline FPS-B1.0 & 8 & 1.0 & $481.25 \pm 52.20^{*}$ \\
\hline FPS-B1.5 & 8 & 1.5 & $670.88 \pm 136.4^{*}$ \\
\hline FPS-B2.0 & 8 & 2.0 & $781.25 \pm 90.10^{*}$ \\
\hline CPS & 8 & None & $289.75 \pm 78.64$ \\
\hline
\end{tabular}

* Statistically significant compared with the CPS group.

in pullout strength between the screw in the FPS-A and FPS-B groups augmented by the same volume of PMMA bone cement. The characteristics of PMMA bone cement distribution (i.e., anterior and lateral $[\mathrm{A}-\mathrm{L}]$ cortex of the $\mathrm{VB}$, posterior cortex of the VB, pedicle of the vertebral arch) and leakage were analyzed using Fisher's exact test between FPS-A1.0 and FPS-B1.0, FPS-A1.5 and FPSB1.5, and FPS-A2.0 and FPS-B2.0; p values $<0.05$ were considered statistically significant. The descriptive statistics are expressed as the mean $\pm \mathrm{SD}$.

\section{Results}

The BMD results showed that all vertebrae used in this study were osteoporotic, with a T-score less than $-2.5 \mathrm{SD}$, and there were no BMD differences among the groups.

\section{Distribution and Cement Leakage Rate of the PMMA}

The distribution of PMMA was assessed by examining 3D CT reconstructions. As shown in Fig. 2, the bone cement around FPS-A formed a conical mass (Fig. 2A and C) that differed from the cylindrical mass (Fig. 2B and D) that was formed around FPS-B. The distribution of PMMA was consistent in each group of FPS-A and FPS-B that was augmented by the same volume PMMA, despite the minor differences in each group.

The distribution characteristics of PMMA bone cement are described in Table 3. When augmented with 1.0, 1.5, and $2.0 \mathrm{ml}$ of PMMA, the amount of leakage that occurred in the FPS-A groups was $0 \%, 0 \%$, and $12.5 \%$, respectively, and in the FPS-B groups, the amount of leakage was $0 \%$ at each augmentation level. However, because of the small sample size of each group in this study, Fisher's exact test revealed no significant difference in the cement distributed to the A-L cortex of the VB, the posterior cortex of the $\mathrm{VB}$, and the pedicle of the vertebral arch, or in the cement leakage between FPS-A1.0 and FPS-B1.0, FPS-A1.5 and FPS-B1.5, and FPS-A2.0 and FPS-B2.0. However, the distributed region was larger in the FPS-A groups than in the FPS-B groups with the same volume of PMMA augmentation. The PMMA that was distributed to the A-L cortex of the VB and the posterior cortex of the VB had a greater potential for leakage. As shown in Table 3, the characteristics of PMMA distribution indicated that $1.5 \mathrm{ml}$ was a relatively safe volume for use in the augmentation. 

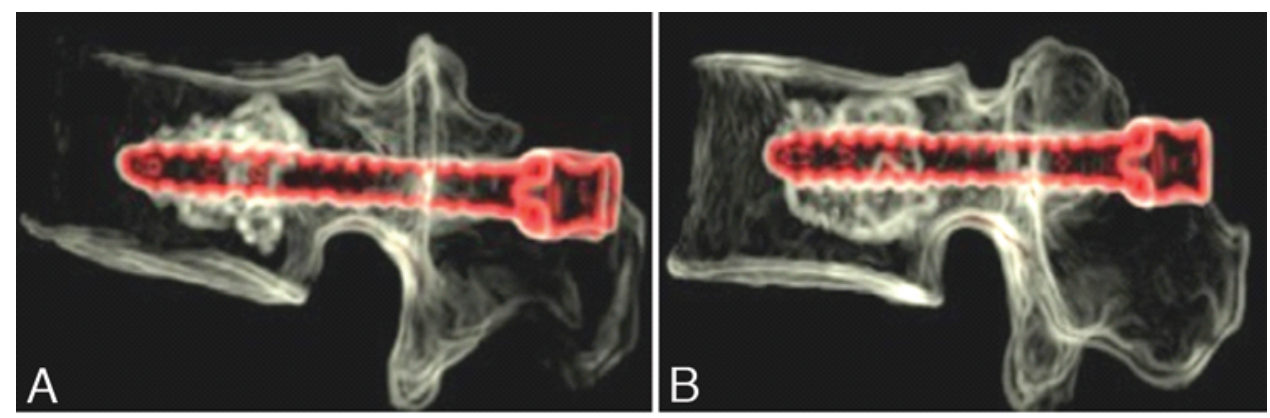

C
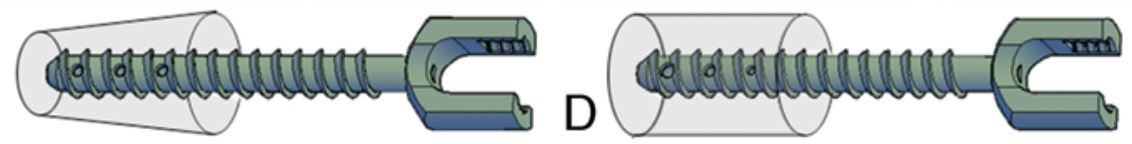

FIG. 2. Reconstructed CT images and schematic images of PMMA distribution. A and C: FPS-A. B and D: FPS-B. Figure is available in color online only.

\section{Pullout Strength}

The $\mathrm{F}_{\max }$ values of the screws are listed in Table 2. The $\mathrm{F}_{\max }$ values in the FPS-A groups were higher than that in the CPS group ( $\mathrm{p}<0.0001)$. Dunnett's multiple-comparisons test demonstrated that, other than the FPS-A1.0 group (adjusted $\mathrm{p}=0.9159$ ), a statistically significant $\mathrm{F}_{\max }$ existed between the FPS-A1.5 group and the CPS group (adjusted $\mathrm{p}=0.0028$ ) and between the FPS-A2.0 group and the CPS group (adjusted $\mathrm{p}<0.0001$ ). Despite the lack of a statistically significant $\mathrm{F}_{\max }$ between FPS-A1.0 and CPS, the $\mathrm{F}_{\max }$ of FPS-A1.0 was approximately $36.5 \%$ higher than the $F_{\max }$ of nonaugmented CPSs. Similarly, one-way ANOVA revealed a statistically significant difference in $\mathrm{F}_{\max }$ between the FPS-B groups and the CPS group ( $p<0.0001$ ). Dunnett's multiple-comparisons test demonstrated that the $\mathrm{F}_{\max }$ values of all the FPS-B groups were significantly higher than those of the CPS group: FPS-B1.0 versus CPS (adjusted $p=0.0358$ ), FPS-B1.5 versus CPS (adjusted $\mathrm{p}<0.0001$ ) and FPS-B2.0 versus CPS (adjusted $\mathrm{p}<0.0001$ ). The mean $\mathrm{F}_{\max }$ increased concomitantly with the increased volume of PMMA when it was augmented in the FPS-A and FPS-B groups. However, the Student t-test indicated that there was only a significant difference between the FPS-A1.0 and FPS-B1.0 groups ( $\mathrm{p}$ $=0.0339$ ), whereas the $\mathrm{F}_{\max }$ values of FPS-B1.5 and FPSB2.0 were higher than those of FPS-A1.5 and FPS-A2.0, respectively $(670.88 \pm 136.4 \mathrm{~N}$ vs $600.63 \pm 170.01 \mathrm{~N}$, and $781.25 \pm 90.10 \mathrm{~N}$ vs $766.50 \mathrm{~N} \pm 165.32 \mathrm{~N})$.

\section{Discussion}

Pedicle screw instrumentation has been widely accepted for the treatment of spinal disorders to restore the stability of the spinal column. However, the successful placement of the screw in the osteoporotic VB remains a challenge for surgeons. The reported loosening rate of the pedicle screw varies from $4.7 \%$ to $25 \% .25,33,35$ The bonescrew interface has been demonstrated as a key factor in screw loosening. ${ }^{12,24}$ To resolve this problem, technologies involving screw design and augmentation, as described above, have been applied.

Recently, FPSs with different designs have been studied in vitro ${ }^{3-5,8-10,12,16,18,26}$ and in vivo. ${ }^{17,14,17,21,24}$ The main difference among these FPSs is the number of side perforations. Regardless of the different number of perforations, the pullout strength of PMMA-augmented FPSs is greater than that of nonaugmented conventional screws $\mathrm{s}^{3,5,9,10,12,26}$ or cannulated screws $s^{8,16,18}$ in the osteoporotic condition. In the present study, compared with the nonaugmented CPS group, FPS-A1.0, 1.5, and 2.0 achieved 137\%, 207\%, and $265 \%$ increased pullout strengths, respectively, and FPS-B1.0, 1.5, and 2.0 achieved 166\%, 232\%, and $269 \%$ increased pullout strengths, respectively. These results are in accordance with those of previous studies. PMMA outflowed from the perforation-integrated PMMA cement, the FPS, and the trabecular bone together. This integral structure can provide a greater anchoring strength of the screw than the interaction between the screw and the osteoporotic trabecular bone.

TABLE 3. The distribution of PMMA bone cement in VBs

\begin{tabular}{cccccc}
\hline & & \multicolumn{4}{c}{ No. of Vertebrae (\%) } \\
\cline { 3 - 6 } Screw Type & No. of Screw Trajectories & A-L Cortex of VB & Posterior Cortex of VB & Pedicle of Vertebral Arch & Leakage \\
\hline FPS-A 1.0 & 8 & $3(37.5)$ & 0 & 0 & 0 \\
\hline FPS-A 1.5 & 8 & $5(62.5)$ & $2(25.0)$ & 0 & 0 \\
\hline FPS-A 2.0 & 8 & $8(100.0)$ & $6(75.0)$ & 0 & $1(12.5)$ \\
\hline FPS-B 1.0 & 8 & $1(12.5)$ & 0 & 0 & 0 \\
\hline FPS-B 1.5 & 8 & $2(25.0)$ & 0 & 0 & 0 \\
\hline FPS-B 2.0 & 8 & $8(100.0)$ & $4(50.0)$ & & 0 \\
\hline
\end{tabular}


The design of diameter-tapered perforations of FPS-B originated from the concept of the canal valve in hydromechanics theory, in which the volume of the fluid that outflows from the valve is correlated with the diameter of the canal and valve. According to this theory, the perforations of FPS-B can adjust the volume of PMMA that outflows from the central bore.

The perforations with the tapered diameter of FPS-B used the different degrees of the openings to control the outflow volume of PMMA. This structure enabled the PMMA around the FPS-B to form an approximately cylindrical mass compared with the conical mass around the FPS-A when augmented by the same volume of PMMA, as illustrated in Fig. 2. The screw-bone interfacial area is theoretically larger for FPS-B than FPS-A, due to the different shapes of the augmented PMMA. The anchoring strength of the screw was mainly increased on the interdigitation of the trabecular bone and PMMA. Hence, a larger screw-bone interfacial area generates a larger screw-anchoring strength. The pullout strength of each FPS-B group was higher than that of the corresponding FPS-A group augmented by the same volume of PMMA, even though the only statistically significant difference existed between FPS-B1.0 and FPS-A1.0. This lack of more significant results may be partially due to the limited sample size in our study.

In addition, PMMA leakage remained the primary concern of the surgeon. The cement leakage was directly related to the volume of PMMA. A literature review indicated that the volume of PMMA used to augment the FPS ranges from 1.5 to $3.0 \mathrm{ml}$ in clinical practice, $1,7,14,17,21,24$ and the reported leakage rate of these clinical trials ranged from $0 \%$ to $23.8 \%$. In the present study, 1.0, 1.5, and 2.0 $\mathrm{ml}$ of PMMA were chosen to investigate the optimal volume of PMMA for augmentation. The results of our study showed that there was no leakage with $1.0-\mathrm{ml}$ and $1.5-\mathrm{ml}$ augmentation in the FPS-A and FPS-B groups and with 2.0-ml augmentation in the FPS-B group. One screw exhibited leakage in the FPS-A2.0 group (12.5\%). The leakage rates of FPS-A and FPS-B were relatively low, which might be attributed to the relatively decreased volume of PMMA bone cement that was used. Table 3 indicates that the cement was $100 \%$ scattered to the A-L cortex of the VB when augmented with $2.0 \mathrm{ml}$ of PMMA bone cement in the FPS-A and FPS-B groups. In the FPS-A2.0 group, the cement in 1 case reached the pedicle during augmentation. It has been demonstrated that cement reaching the pedicle area leads to a higher risk for canal leakage. ${ }^{17}$ However, when augmented with $1.5 \mathrm{ml}$ of PMMA bone cement, none of the cement reached the pedicle. In addition, there was no significant difference in pullout strength between FPS-B2.0 and FPS-A2.0. Hence, we concluded that the ideal volume for augmentation is $1.5 \mathrm{ml}$ and less than $2.0 \mathrm{ml}$ in lumbar vertebrae (considering thoracic vertebra volume was smaller than the lumbar vertebra volume). Table 3 also shows that the cement spread zone in the VB of the FPS-B groups was smaller than that of the FPS-A groups. It is apparent that the greater potential for PMMA to be distributed to the posterior two-thirds of the VB can be attributed to the equal diameter of the perforations of FPS-A. There was no volume restriction in the outflow of PMMA bone cement from each perforation at the same diameter during augmentation. PMMA bone cement would outflow from the most proximal perforations of the screw if there had been no impediment in periperforations. ${ }^{9}$ This modification could allow the PMMA bone cement to scatter to the back of the VB near its posterior margin and into the pedicle arch, even leaking into the spinal canal or intervertebral foramen. ${ }^{7}$ However, FPS-B with diameter-tapered perforations could ameliorate the adverse PMMA distribution found in FPS-A. The smallest diameter of the proximal perforations would restrict the amount of PMMA bone cement outflow, enabling more PMMA bone cement to outflow from the distal perforations into the middle-anterior VB. The middle-anterior is a much safer region and has a decreased potential for cement leakage than the posterior region of the VB.

There are several limitations of the current study. First, our study was carried out in cadaveric vertebrae; thus, it might not represent the in vivo situation, even though the pullout test was conducted according to standard ASTM F543-07 and has been used in various studies to evaluate the mechanical properties of pedicle screws. Further study under conditions that mimic the physiological fatigue loading situation is required. In addition, because of the specimen limitation, the 2 pedicles in 1 vertebra were randomized into different groups to implant different screws. The order of the pullout test may have affected the results. The first-pulled screws might affect the contralateral bone-anchoring power of the other screw. However, we only compared the pullout strength of augmented FPS with that of nonaugmented CPS. A comparison between augmented FPS and augmented CPS will be necessary in future studies.

\section{Conclusions}

The FPS-B with diameter-tapered perforations may be the optimal design for the instrumentation in the osteoporotic VB. The cylindrical distribution of the augmented PMMA around the FPS-B regulated by diameter-tapered perforations not only provided higher pullout strength when compared with CPS but also reduced the potential for cement leakage when compared with FPS-A. Although the pullout test demonstrated that statistical significance was only reached between FPS-A1.0 and FPS-B1.0, $1.5 \mathrm{ml}$ of PMMA was considered to be a reasonable augmentation volume with respect to the characteristics of augmented cement distribution associated with cement leakage. Despite the advantages of FPS-B that were observed in the present study, further work on the simulated and actual physiological situation is required to verify these findings.

\section{Acknowledgments}

This study was sponsored by the Research Fund for the National Natural Science Foundation of China (No. 31170913/ C1002).

\section{References}

1. Amendola L, Gasbarrini A, Fosco M, Simoes CE, Terzi S, De Iure F, et al: Fenestrated pedicle screws for cement-augmented purchase in patients with bone softening: a review of 21 cases. J Orthop Traumatol 12:193-199, 2011 
2. Aydogan M, Ozturk C, Karatoprak O, Tezer M, Aksu N, Hamzaoglu A: The pedicle screw fixation with vertebroplasty augmentation in the surgical treatment of the severe osteoporotic spines. J Spinal Disord Tech 22:444-447, 2009

3. Becker S, Chavanne A, Spitaler R, Kropik K, Aigner N, Ogon M, et al: Assessment of different screw augmentation techniques and screw designs in osteoporotic spines. Eur Spine J 17:1462-1469, 2008

4. Blattert TR, Glasmacher S, Riesner HJ, Josten C: Revision characteristics of cement-augmented, cannulated-fenestrated pedicle screws in the osteoporotic vertebral body: a biomechanical in vitro investigation. Technical note. J Neurosurg Spine 11:23-27, 2009

5. Bullmann V, Schmoelz W, Richter M, Grathwohl C, Schulte TL: Revision of cannulated and perforated cement-augmented pedicle screws: a biomechanical study in human cadavers. Spine (Phila Pa 1976) 35:E932-E939, 2010

6. Burval DJ, McLain RF, Milks R, Inceoglu S: Primary pedicle screw augmentation in osteoporotic lumbar vertebrae: biomechanical analysis of pedicle fixation strength. Spine (Phila Pa 1976) 32:1077-1083, 2007

7. Chang MC, Kao HC, Ying SH, Liu CL:

Polymethylmethacrylate augmentation of cannulated pedicle screws for fixation in osteoporotic spines and comparison of its clinical results and biomechanical characteristics with the needle injection method. J Spinal Disord Tech 26:305-315, 2013

8. Chao KH, Lai YS, Chen WC, Chang CM, McClean CJ, Fan CY, et al: Biomechanical analysis of different types of pedicle screw augmentation: a cadaveric and synthetic bone sample study of instrumented vertebral specimens. Med Eng Phys 35:1506-1512, 2013

9. Chen LH, Tai CL, Lai PL, Lee DM, Tsai TT, Fu TS, et al: Pullout strength for cannulated pedicle screws with bone cement augmentation in severely osteoporotic bone: influences of radial hole and pilot hole tapping. Clin Biomech (Bristol, Avon) 24:613-618, 2009

10. Chen LH, Tai CL, Lee DM, Lai PL, Lee YC, Niu CC, et al: Pullout strength of pedicle screws with cement augmentation in severe osteoporosis: a comparative study between cannulated screws with cement injection and solid screws with cement pre-filling. BMC Musculoskelet Disord 12:33, 2011

11. Cheng LM, Wang JJ, Zeng ZL, Zhu R, Yu Y, Li C, et al: Pedicle screw fixation for traumatic fractures of the thoracic and lumbar spine. Cochrane Database Syst Rev 5:CD009073, 2013

12. Choma TJ, Pfeiffer FM, Swope RW, Hirner JP: Pedicle screw design and cement augmentation in osteoporotic vertebrae: effects of fenestrations and cement viscosity on fixation and extraction. Spine (Phila Pa 1976) 37:E1628-E1632, 2012

13. Frankel BM, Jones T, Wang C: Segmental polymethylmethacrylate-augmented pedicle screw fixation in patients with bone softening caused by osteoporosis and metastatic tumor involvement: a clinical evaluation. Neurosurgery 61:531538, 2007

14. Fransen P: Increasing pedicle screw anchoring in the osteoporotic spine by cement injection through the implant. Technical note and report of three cases. J Neurosurg Spine 7:366-369, 2007

15. Gao M, Lei W, Wu Z, Liu D, Shi L: Biomechanical evaluation of fixation strength of conventional and expansive pedicle screws with or without calcium based cement augmentation. Clin Biomech (Bristol, Avon) 26:238-244, 2011

16. Goost H, Deborre C, Wirtz DC, Burger C, Prescher A, Fölsch $\mathrm{C}$, et al: PMMA-augmentation of incompletely cannulated pedicle screws: a cadaver study to determine the benefits in the osteoporotic spine. Technol Health Care 22:607-615, 2014

17. Hu MH, Wu HT, Chang MC, Yu WK, Wang ST, Liu CL:
Polymethylmethacrylate augmentation of the pedicle screw: the cement distribution in the vertebral body. Eur Spine J 20:1281-1288, 2011

18. Kueny RA, Kolb JP, Lehmann W, Püschel K, Morlock MM, Huber G: Influence of the screw augmentation technique and a diameter increase on pedicle screw fixation in the osteoporotic spine: pullout versus fatigue testing. Eur Spine J 23:2196-2202, 2014

19. Lai PL, Tai CL, Chen LH, Nien NY: Cement leakage causes potential thermal injury in vertebroplasty. BMC Musculoskelet Disord 12:116, 2011

20. Liu D, Wu ZX, Pan XM, Fu SC, Gao MX, Shi L, et al: Biomechanical comparison of different techniques in primary spinal surgery in osteoporotic cadaveric lumbar vertebrae: expansive pedicle screw versus polymethylmethacrylateaugmented pedicle screw. Arch Orthop Trauma Surg 131:1227-1232, 2011

21. Lubansu A, Rynkowski M, Abeloos L, Appelboom G, Dewitte O: Minimally invasive spinal arthrodesis in osteoporotic population using a cannulated and fenestrated augmented screw: technical description and clinical experience. Minim Invasive Surg 2012:507826, 2012

22. Manbachi A, Cobbold RS, Ginsberg HJ: Guided pedicle screw insertion: techniques and training. Spine J 14:165-179, 2014

23. Mehta H, Santos E, Ledonio C, Sembrano J, Ellingson A, Pare P, et al: Biomechanical analysis of pedicle screw thread differential design in an osteoporotic cadaver model. Clin Biomech (Bristol, Avon) 27:234-240, 2012

24. Moon BJ, Cho BY, Choi EY, Zhang HY: Polymethylmethacrylate-augmented screw fixation for stabilization of the osteoporotic spine: a three-year follow-up of 37 patients. J Korean Neurosurg Soc 46:305-311, 2009

25. Ohtori S, Inoue G, Orita S, Yamauchi K, Eguchi Y, Ochiai N, et al: Comparison of teriparatide and bisphosphonate treatment to reduce pedicle screw loosening after lumbar spinal fusion surgery in postmenopausal women with osteoporosis from a bone quality perspective. Spine (Phila Pa 1976) 38:E487-E492, 2013

26. Paré PE, Chappuis JL, Rampersaud R, Agarwala AO, Perra $\mathrm{JH}$, Erkan S, et al: Biomechanical evaluation of a novel fenestrated pedicle screw augmented with bone cement in osteoporotic spines. Spine (Phila Pa 1976) 36:E1210-E1214, 2011

27. Ponnusamy KE, Iyer S, Gupta G, Khanna AJ: Instrumentation of the osteoporotic spine: biomechanical and clinical considerations. Spine J 11:54-63, 2011

28. Rohmiller MT, Schwalm D, Glattes RC, Elalayli TG, Spengler DM: Evaluation of calcium sulfate paste for augmentation of lumbar pedicle screw pullout strength. Spine $\mathbf{J}$ 2:255-260, 2002

29. Sandén B, Olerud C, Petrén-Mallmin M, Larsson S: Hydroxyapatite coating improves fixation of pedicle screws. A clinical study. J Bone Joint Surg Br 84:387-391, 2002

30. Sarzier JS, Evans AJ, Cahill DW: Increased pedicle screw pullout strength with vertebroplasty augmentation in osteoporotic spines. J Neurosurg 96 (3 Suppl):309-312, 2002

31. Sawakami K, Yamazaki A, Ishikawa S, Ito T, Watanabe K, Endo N: Polymethylmethacrylate augmentation of pedicle screws increases the initial fixation in osteoporotic spine patients. J Spinal Disord Tech 25:E28-E35, 2012

32. Upasani VV, Farnsworth CL, Tomlinson T, Chambers RC, Tsutsui S, Slivka MA, et al: Pedicle screw surface coatings improve fixation in nonfusion spinal constructs. Spine (Phila Pa 1976) 34:335-343, 2009

33. Wu JC, Huang WC, Tsai HW, Ko CC, Wu CL, Tu TH, et al: Pedicle screw loosening in dynamic stabilization: incidence, risk, and outcome in 126 patients. Neurosurg Focus 31(4):E9, 2011 
34. Wu ZX, Cui G, Lei W, Fan Y, Wan SY, Ma ZS, et al: Application of an expandable pedicle screw in the severe osteoporotic spine: a preliminary study. Clin Invest Med 33:E368E374, 2010

35. Wu ZX, Gong FT, Liu L, Ma ZS, Zhang Y, Zhao X, et al: A comparative study on screw loosening in osteoporotic lumbar spine fusion between expandable and conventional pedicle screws. Arch Orthop Trauma Surg 132:471-476, 2012

\section{Disclosures}

The authors report no conflict of interest concerning the materials or methods used in this study or the findings specified in this paper.

\section{Author Contributions}

Conception and design: W Lei, ZX Wu. Acquisition of data: QC Tan, JW Wu, F Peng. Analysis and interpretation of data: QC Tan, JW Wu, F Peng, Y Zang, Y Li, ZX Wu. Drafting the article: QC Tan, JW Wu. Critically revising the article: W Lei, X Zhao. Reviewed submitted version of manuscript: W Lei, QC Tan, Y $\mathrm{Li}, \mathrm{X}$ Zhao, ZX Wu. Approved the final version of the manuscript on behalf of all authors:W Lei. Statistical analysis: QC Tan, JW Wu. Administrative/technical/material support: F Peng, Y Zang. Study supervision: W Lei, X Zhao, ZX Wu.

\section{Correspondence}

Wei Lei, Department of Orthopaedics, Xijing Hospital, No. 127 Changlexi Rd., Xi' an Shaanxi Province 710032, People's Republic of China. email: leiwei@fmmu.edu.cn. 